\title{
Platelet activation via PAR4 is involved in the initiation of thrombin generation and in clot elasticity development
}

\author{
Karin Vretenbrant, Sofia Ramström, Maria Bjerke and Tomas Lindahl
}

\section{Linköping University Post Print}

N.B.: When citing this work, cite the original article.

Original Publication:

Karin Vretenbrant, Sofia Ramström, Maria Bjerke and Tomas Lindahl, Platelet activation via PAR4 is involved in the initiation of thrombin generation and in clot elasticity development, 2007, Thrombosis and Haemostasis, (97), 3, 417-424.

http://dx.doi.org/10.1160/TH06-07-0397

Copyright: Schattauer

http://www.schattauer.de/

Postprint available at: Linköping University Electronic Press

http://urn.kb.se/resolve?urn=urn:nbn:se:liu:diva-39478 


\title{
Platelet activation via PAR4 is involved in the initiation of thrombin generation and in clot elasticity development
}

\author{
Karin Vretenbrant', Sofia Ramström', Maria Bjerke², Tomas L. Lindahl', 2 \\ 'Department of Biomedicine and Surgery, Division of Clinical Chemistry, University Hospital, Linköping, Sweden; ${ }^{2}$ Department of Clinical \\ Chemistry, Laboratory Medicine, University Hospital, Linköping, Sweden
}

\begin{abstract}
Summary
Thrombin is a pivotal enzyme formed in the coagulation cascade and an important and potent platelet activator. The two protease-activated thrombin receptors on human platelets are denoted PARI and PAR4. The physiological relevance of PAR4 is still unclear, as both aggregation and secretion can be accomplished by PARI activation alone. In the present study we have investigated the role of PARs in platelet activation, blood coagulation, clot elasticity and fibrinolysis. Flow cytometry, free oscillation rheometry and thrombin generation measurements were used to analyze blood or platelet-rich plasma from healthy individuals. Maximum PARI activation with the peptide SFLLRN gave fewer fibrinogen-binding platelets with lower mean fluorescent intensity than maximum PAR4 activation with AYPGKF.
\end{abstract}

\section{Keywords}

Blood coagulation, clot elasticity, fibrinolysis, PAR receptors
Inhibition of any of the receptors prolonged clotting times. However, PARI is more important for fibrinolysis; inhibition of this receptor prolonged all the steps in the fibrinolytic process. Clot elasticity decreased significantly when the PAR4 receptor was inhibited. In the thrombin generation measurements, PAR4 inhibition delayed the thrombin generation start and peak, but did not affect the total amount of thrombin generated. PARI inhibition had no significant impact on thrombin generation. We found that PAR4 is most likely activated by low concentrations of thrombin during the initial phase of thrombin generation and is of importance to the clotting time. Furthermore, we suggest that the PAR4 receptor may have a physiological role in the stabilisation of the coagulum.

\section{Introduction}

Platelets have several functions that are important for haemostasis. Following a vessel wall injury, platelets adhere to exposed subendothelial structures at the damaged site. More platelets are recruited, and an aggregate is formed. Simultaneously exposed tissue factor initiates the coagulation by binding factor VIIa and activating factors IX and X, which leads to the formation of thrombin and, ultimately, cross-linked fibrin from fibrinogen. Platelets also play an important role in the propagation and amplification of coagulation as the tenase and prothrombinase complexes are formed on the surface of activated platelets.

Thrombin, formed in the coagulation cascade, is a strong platelet activator. Therefore, a positive feedback loop facilitates the formation of more thrombin at the injured site (reviewed by [1]). There are at least three platelet receptors for thrombin: GP1b $\alpha$ and the protease-activated receptors (PAR) 1 and 4. Both PARs belong to the seven transmembrane family of G-protein-linked receptors and have been cloned and sequenced. Both are coupled to $\mathrm{G} \alpha \mathrm{q}$ and $\mathrm{G} \alpha_{12 / 13}$ (2). Thrombin cleaves the receptors within the large N-terminal extra-cellular domain, creating new amino terminals, SFLLRN and GYPGQV $(3,4)$. The new N-terminus formed by thrombin cleavage serves as a "tethered ligand" (5), which binds intramolecularly and causes receptor activation (PAR1 [6], PAR4 [7]). Specific agonist peptides, mimicking the new N-terminus, have been designed; for PAR1 the most frequently used is SFLLRN (8), whereas for PAR4 the most potent is AYPGKF (9). If both cleavage sites are blocked by antibodies which is sponsored by the County Council of Östergötland and the University of Linköping. Parts of this work have been a project within the Biomedical Research School, Linköping University, which was supported by the Swedish Foundation 
raised against peptides spanning the cleavage sites, the platelet response to thrombin is abolished (10).

According to a biphasic model for thrombin-induced platelet activation, PAR1 is activated by the low thrombin concentration achieved early on (11), possibly aided by binding to GPIb $\alpha$ (12). We have previously reported that a very low concentration of thrombin, $0.028 \mathrm{nM}$, was sufficient to induce $50 \%$ of maximum PAR1 cleavage (13). As the coagulation proceeds, more thrombin is formed, and the low-affinity receptor, PAR4, is cleaved and activated. This cleavage of PAR4 might be facilitated by PAR1 (14).

The physiological role of PAR4 is still unclear, because secretion and aggregation can be accomplished by PAR1 activation alone. Activation of platelets by thrombin induces procoagulant changes of the platelet surface, but the procoagulant activity of purified thrombin-degranulated platelets was greater than that of SFLLRN-degranulated platelets (15), which indicates that thrombin has additional mechanisms to induce procoagulant activity. It has also been suggested that PAR4 might be a target for cathepsin G, which is involved in neutrophil-dependent platelet activation (16). PAR4 has also been hypothesised to play a role in aggregate stabilisation (17). In this study we investigated and compared the impact of PAR1 and PAR4 activation and inhibition on platelet activation, blood coagulation, clot elasticity and fibrinolysis resistance.

\section{Materials and methods}

Four-channel $10 \mathrm{~Hz}$ free oscillation rheometers (FOR) ReoRox $^{\circledR} 4(18,19)$, disposable gold- plated polypropylene sample cups, gold-plated reaction chambers for bob experiments and software $\left(\operatorname{ReoRox}^{\circledR} 4\right.$ v. 2.00 and ReoRox ${ }^{\circledR} 4$ Viewer v. $2.11 \mathrm{k}$ ) from MediRox, Nyköping, Sweden were used. In this rheometer, oscillation is initiated by a forced turn of the sample cup every 2.5 seconds (sec). After a brief holding time, the sample cup is released, allowing rotational oscillation with very low friction around the longitudinal axis. An optic angular sensor records the frequency $(\mathrm{Fq})$ and damping $(\mathrm{D})$ of the oscillation as a function of time. This is plotted as a curve, from which the time for different curve features may be determined.

By definition, the clotting time is when fibrin fibres have started to form in the sample. This increases the viscosity of the sample, which leads to a decrease in the frequency and an increase in the damping of the oscillation. The "high sensitivity state detector" was used as clotting-time detector in this study. The clotting time determined by this detector correlates extremely well with the manual reference method of visual clot detection, $\mathrm{r}^{2}=0.97$ (20). The starting and endpoints of the fibrinolysis process were determined using Lysview, a computer program developed in-house. The fibrinolysis starting point is when the fibrin fibres in the clot have started to degrade. This decreases the viscosity of the sample, which leads to an increase in frequency and an increase in the damping of the oscillation. The fibrinolysis endpoint is when all fibrin fibres have been degraded, and the frequency and damping have returned to the same values as in the sample prior to coagulation.

The coagulation process creates fibrin fibres that couple the cup wall to the bob, resulting in an increased frequency and damping of the oscillation as the elasticity of the coagulum rises.

The elasticity measurements were analysed in rh_pro, a computer program developed in-house. In this program the elasticity modulus $\left(\mathrm{G}^{\prime}\right)$ is plotted as a function of time. From this curve two specific curve features can be determined, $\Delta \mathrm{G}^{\prime}$ and $\mathrm{G}^{\prime}$ max. $\Delta \mathrm{G}^{\prime}$ $(\mathrm{Pa} / \mathrm{min})$ is the maximum change in elasticity achieved during clot development, i.e. where the curve slope reaches its highest value. $\mathrm{G}^{\prime} \max (\mathrm{Pa})$ is the $\mathrm{G}^{\prime}$ value read at the point at which the increase has become less than 1 Pascal per second, which is when the elasticity has reached its maximum. Typical curves are shown in (21).

Flow cytometry was performed on a Coulter Epics XL-MCL Flow Cytometer with Expo 32 ADC software from Beckman Coulter (Miami, FL, USA).

Phycoerythrin-conjugated mouse antibodies against $\mathrm{GPIb}$ (CD42b) were purchased from Dako AS (Glostrup, Denmark). The fluorescein (FITC)-conjugated chicken antibody towards human fibrinogen and the lysing solution were from Diapensia HB (Linköping, Sweden). The FITC-conjugated mouse antibody against human P-selectin (CD62P) and SPAN12 antibody was purchased from Immunotech (Marseilles, France). The PAR4-blocking antibody (IgG fraction purified from egg yolk) and a control solution of unspecific IgY were prepared and kindly provided by Anders Larsson at the Department of Clinical Chemistry, University of Uppsala, Sweden. In brief, three laying white leghorn hens were immunised with the PAR4-peptide [2.0 $\mathrm{mg}$ conjugated to $6.6 \mathrm{mg}$ of hemocyanin (Concholepas concholepas)]. The hens received one immunisation with Freund's complete adjuvant and three booster injections with incomplete adjuvant. After the immunisation period the eggs from the three hens were collected, and the antibodies were purified from the egg yolk by the polyethylene glycol (PEG) method (22). Chicken antibodies, in contrast to mammalian, do not cause platelet activation per se and are less prone to cause artefacts (23).

The anticoagulant citrate (citric acid 1-hydrate and trisodium citrate hydrate) and $\mathrm{CaCl}_{2} \times 2 \mathrm{H}_{2} \mathrm{O}$ were obtained from E.Merck (Darmstadt, Germany). Recombinant hirudin (lepirudin, Reflu$\operatorname{dan}^{\circledR}$ ) was from Aventis (Strasbourg, France). Sodium chloride, Braun $9 \mathrm{mg} / \mathrm{ml}$, was obtained from B.Brown, Medical AB (Bromma, Sweden). Chemicals for the HEPES buffer $(137 \mathrm{mM}$ $\mathrm{NaCl}, 2.7 \mathrm{mM} \mathrm{KCl}, 1 \mathrm{mM} \mathrm{MgCl}$, $5.6 \mathrm{mM}$ glucose, $1 \mathrm{~g} / 1$ bovine serum albumin and $20 \mathrm{mM}$ HEPES (N-[2-hydroxyethyl] piperazine-N'-[2-ethanesulphonic acid]), $\mathrm{pH}$ 7.40) were obtained from Sigma Chemical Company (St. Louis, MO, USA).

The PAR1-AP (SFLLRN) and the PAR4-AP (AYPGKF) were synthesised by the Biotechnology Centre of Oslo. The PAR1 antagonist SCH79797 dihydrochloride (N3-Cyclopropyl-7-[4-(1methylethyl) phenyl] methyl-7H-pyrrolo [3,2-f]quinazoline-1,3-diamine dihydrochloride) was obtained from Tocris Cookson Ltd. (Bristol, UK). The fibrinolytic activator, recombinant human tissue plasminogen activator (t-PA) (alteplase, Actilyse $^{\circledR}$ ) was obtained from Boerhringer Ingelheim (Ingelheim, Germany). Human thrombin (1370 NIH units/mg protein) was purchased from Sigma Aldrich Co. All solutions except the antibodies were portioned and kept at $-70^{\circ} \mathrm{C}$ until the time of use. The antibodies were kept at $+4^{\circ} \mathrm{C}$. 


\section{Blood sampling}

For the FOR experiments venous blood was collected with minimum trauma and stasis via a 21 -gauge needle in 4.5 -ml plastic vacuum tubes (S-Monovette ${ }^{\circledR}$, Sarstedt, Nümbrecht, Germany) prefilled with tri-sodium citrate $130 \mathrm{mM}$. This yielded a final citrate concentration of $13 \mathrm{mM}$. In the thrombin generation measurements, the final citrate concentration was $10.5 \mathrm{mM}$, as recommended by the manufacturer. For the flow cytometry experiments, $500 \mu \mathrm{l}$ of recombinant hirudin $(2,000 \mathrm{ATU} / \mathrm{ml})$ was added to the tubes before blood collection, yielding a final concentration of $200 \mathrm{ATU} / \mathrm{ml}$. All blood donors gave informed consent to blood sampling. The blood collection protocol was approved by the ethics committee at Linköping University Hospital. Platelet-rich plasma (PRP) was obtained by centrifugation at $140 \mathrm{x}$ g for 20 minutes (min) at room temperature.

\section{Flow cytometry}

Platelet activation was measured as platelet-bound fibrinogen and CD62P expression on the platelet surface utilising flow cytometry. Ten $\mu$ l of well-mixed whole blood anticoagulated with hirudin $(200 \mathrm{ATU} / \mathrm{ml})$ was transferred to plastic tubes containing FITC-conjugated antibodies against human fibrinogen (final concentration $2 \mu \mathrm{g} / \mathrm{ml}$ ) or anti-CD62P (final concentration $0.24 \mu \mathrm{g} / \mathrm{ml}$ ), mouse anti-CD42b-phycoerythrin antibody (final concentration $1.8 \mu \mathrm{g} / \mathrm{ml}$ ) and HEPES buffer to a final volume of $90 \mu \mathrm{l}$. After $10 \mathrm{~min} 10 \mu \mathrm{l}$ of PAR1-AP or PAR4-AP was added to the samples at exact time intervals. The final concentrations were $0-100 \mu \mathrm{M}$ of PAR1-AP and $0-500 \mu \mathrm{M}$ of PAR4-AP. After exactly $10 \mathrm{~min}$, the reaction was stopped by the addition of $1,000 \mu \mathrm{l}$ of lysing solution. The samples were left for another $10 \mathrm{~min}$ to lyse the erythrocytes, and were thereafter diluted 1:5 in lysing solution before analysis on the flow cytometer. All steps were performed at room temperature and without stirring the samples. The platelet population was identified using its forward light scatter and fluorescence (CD42b-phycoerythrin). A cut-off was pre-set in the FITC fluorescence channel to divide the platelet population containing non-binding antibody with corresponding fluorescence intensity into two fractions: one that contained $98.5-99.5 \%$ of the platelets and the other containing the brightest $0.5-1.5 \%$ of the platelets. Platelets with fluorescence intensity higher than the pre-set cut-off were identified as fibrinogen-binding or CD62P-positive cells. All samples were run in duplicate.

In the same flow cytometry experiment the mean intensity of the fluorescence (MFI) for the whole platelet population was also analysed. The MFI value, an arbitrary unit which depends on the brand of the flow cytometer, shows the mean fluorescence signal from individual platelets. This correlates to the number of fluorescent antibodies that have bound to the platelet surface. One sample that produced an MFI value of 13.3 in the flow cytometer used in the present study registered 126.67 on a FACSCalibur using CellQuest software (Becton Dickinson, Palo Alto, CA, USA.)

When the clot and fibrinolysis experiments were performed, samples from a number of blood donors underwent control measurements in the flow cytometer to confirm the degree of activation with and without the presence of PAR1 and PAR4 inhibitors. Activation was measured as the fibrinogen binding on the platelet surface. The procedure was the same as for the platelet activation experiments, although the PAR1 antagonist and PAR4-blocking antibody were present from the start (final concentration $18 \mu \mathrm{M}$ and $1.0 \mathrm{mg} / \mathrm{ml}$, respectively), and thrombin was used as the activator (final concentration $2 \mathrm{nM}$ and $50 \mathrm{nM}$, respectively). To test for any agonist effect by the PAR inhibitors, the same flow cytometric assay as above was used, but without thrombin being added.

A SPAN12 antibody was used to check the PAR4-blocking antibody specificity for PAR4. SPAN12 binds only to uncleaved PAR1 (24-26). In the SPAN12 experiment, whole blood incubated with PAR4-blocking antibody $(1 \mathrm{mg} / \mathrm{ml})$ or unspecific $\operatorname{IgY}$ $(1 \mathrm{mg} / \mathrm{ml})$ was activated with thrombin $(2 \mathrm{nM})$. After $5 \mathrm{~min}$, SPAN12 $(2 \mu \mathrm{g} / \mathrm{ml})$ was added, and after $10 \mathrm{~min}$ the amount of bound SPAN12 was measured in the flow cytometer. The procedure was slightly modified from (13).

\section{FOR experiments}

\section{Fibrinolysis experiments}

Fibrinolysis experiments were performed on blood samples from ten different donors. In each experiment ten gold-coated cups were used. Every cup was pre-filled with $\mathrm{CaCl}_{2}$ (final concentration $10 \mathrm{mM}$ to restore the physiological calcium activity), thrombin (final concentration $2 \mathrm{nM}$ ), and t-PA (final concentration $70 \mathrm{U} / \mathrm{ml})$. The blood $(500 \mu \mathrm{l})$ was incubated at room temperature for $10 \mathrm{~min}$ with either PAR1 antagonist SCH79797 $(18 \mu \mathrm{M})$ (the same volume of sodium chloride in the control) or PAR4-blocking antibody $(1.0 \mathrm{mg} / \mathrm{ml})$ (the same concentration of isotype antibody in the control) or both $(1.0 \mathrm{mg} / \mathrm{ml}$ of isotype antibody in the control). Such blood was added to the cup and mixed with the other substances before the cup was placed in the rheometer. Each sample was analysed in duplicate. The clotting time, and the fibrinolysis starting and endpoints were analysed in the ReoRox ${ }^{\mathbb{}} 4$-Viewer program and in the Lysview program.

\section{Elasticity measurements}

The elasticity experiments were performed on blood samples from ten different donors. Gold-coated reaction chambers were used for all experiments. The reaction chambers were first placed in the rheometer. All the substances $\left(\mathrm{CaCl}_{2} 10 \mathrm{mM}\right.$, thrombin $2 \mathrm{nM}$, and whole blood previously incubated with either PAR1 antagonist SCH79797 $18 \mu \mathrm{M}$ or PAR4-blocking antibody $1.0 \mathrm{mg} / \mathrm{ml}$, all final concentrations, or controls as above) were mixed before they were injected into the reaction chamber with a 1-ml plastic disposable syringe. The results from the elasticity measurements were analysed in the ReoRox ${ }^{\circledR} 4$-Viewer program and rh_pro.

\section{Thrombin generation measurements in PRP}

The thrombin generation test is based on a 96-well plate filled with PRP-samples to which Thrombin Calibrator or PPP/PRP trigger is added. The instrument dispenses a mixture of fluorogenic substrate and calcium, and coagulation begins. Finally, the analysis program calculates all the parameters of the thrombogram and expresses the result in nanomolar thrombin in time (27). The thrombin generation measurements were performed using a Fluoroskan Ascent FL (Thermo Electron Corporation, 


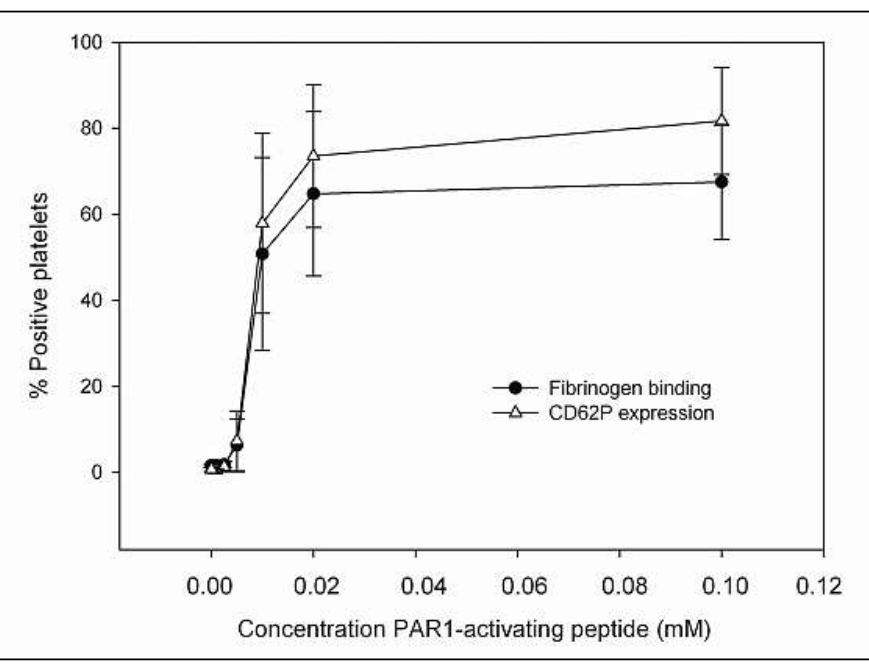

Figure I: Platelet activation measurements performed with flow cytometry on whole blood anticoagulated with hirudin. The diagram shows fibrinogen binding and CD62P expression as a result of activation with different concentrations of the PARI-AP SFLLRN. The results are mean \pm SD for seven healthy donors.

Vantaa, Finland) with Thrombinoscope software (Thrombinoscope, Maastricht, Netherlands). Measurements were performed according to the manufacturer's instructions using the PRP reagent, which had a final concentration of $0.5 \mathrm{pM}$ tissue factor. PAR1 antagonist SCH79797 25.2 $\mu \mathrm{M}$, PAR4-blocking antibody $1.4 \mathrm{mg} / \mathrm{ml}$, a combination of both, or an irrelevant antibody $(1.4 \mathrm{mg} / \mathrm{ml})$ were added to the PRP and preincubated for $10 \mathrm{~min}$ before the start of the experiment. The inhibitor concentrations were recalculated to give a plasma concentration similar to that in the whole-blood experiments assuming a haematocrit of $40 \%$. All samples were analysed in triplicate.

\section{Statistics}

Data were analysed using SPSS 11.5.1 for Windows, (SPSS, Inc., Chicago, IL, USA). Due to the rather small number of individuals and the considerable inter-individual variation, comparisons between groups were made with the non-parametric Wilcoxon Matched Pairs test, which does not assume a normal distribution. Comparisons were only made between sample and control from the same individual as the individual variation was pronounced.

\section{Results}

The inhibitors were tested in different concentrations. The concentration chosen for further experiment was that with maximum inhibition, but not higher than necessary. In control experiments by flow cytometry, PAR1 antagonist and PAR4-blocking antibody were added in the absence of an activator to detect any possible agonistic effect. No agonistic effect, measured as fibrinogen-binding cells, was detected with the chosen concentrations (data not shown).

SPAN12 is an antibody that only binds to the platelet PAR1 receptor when it is not cleaved by thrombin (24-26). In a control experiment by flow cytometry, the amount of SPAN12 binding

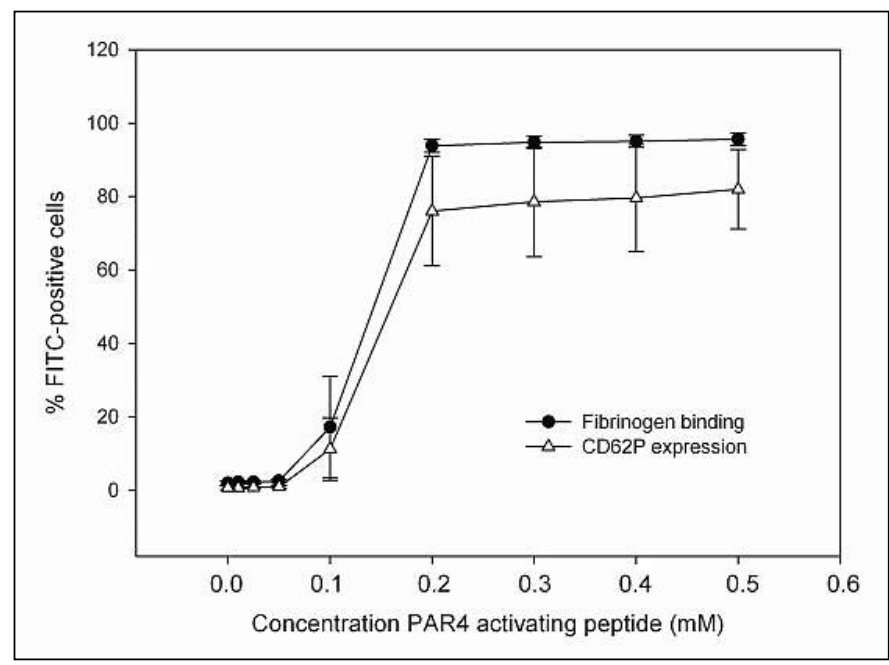

Figure 2: Platelet activation measurements performed with flow cytometry on whole blood anticoagulated with hirudin. The diagram shows fibrinogen binding and CD62P expression as a result of activation with different concentrations of the PAR4-AP AYPGKF. The results are mean \pm SD for nine healthy donors.

was the same in the presence of the PAR4-blocking antibody as in its absence. Unactivated samples were set as $100 \%$ SPAN12 binding; samples activated with thrombin $2 \mathrm{nM}$ resulted in $35 \%$ SPAN12 binding in the absence of PAR4-blocking antibody. When the PAR4-blocking antibody and the isotype antibody were present, the SPAN12 binding was $32 \%$. This indicates that the PAR4-blocking antibody does not affect the cleavage of PAR1.

\section{PAR4 activation induced more platelet-fibrinogen binding than PARI activation as revealed by flow cytometry}

The maximum response to the PAR1-AP SFLLRN was $68 \pm$ $13 \%$ (mean $\pm \mathrm{SD}$ ) fibrinogen-binding platelets and $82 \pm 12 \%$ CD62P-exposing platelets, respectively, $n=7$ (Fig. 1). The maximum response to the PAR4-AP AYPGKF was $96 \pm 2 \%$ fibrinogen-binding platelets and $82 \pm 11 \%$ CD62 exposing cells, respectively, $n=9$ (Fig. 2).

The MFI value increased with increasing concentration of activating peptide. The maximum MFI values for the PAR1-AP were $2.1 \pm 0.6$ for fibrinogen binding and $3.1 \pm 0.7$ for CD62P exposure, respectively, $\mathrm{n}=7$. For PAR4-AP the maximum MFI values were $4.9 \pm 1.3$ and $3.1 \pm 1.2$ for fibrinogen binding and CD62P exposure, respectively, $\mathrm{n}=9$. EC50 for PAR1-AP was $8.38 \mu \mathrm{M}$ for fibrinogen binding and $8.40 \mu \mathrm{M}$ for CD62P expression. For PAR4-AP the EC50 was $0.13 \mathrm{mM}$ for fibrinogen binding and $0.14 \mathrm{mM}$ for CD62P expression.

\section{Effects of PARI and PAR4 inhibition on clotting times and fibrinolysis}

The clotting and fibrinolysis times following activation by thrombin and inhibition of the PAR1 receptor with PAR1 antagonist are shown in Table 1. To be able to visualise the differences between control and samples with inhibitors for different donors, the data were normalised, with the time for the corresponding 
Table I: Results from FOR analysis of clotting time, fibrinolysis and coagulum elasticity in blood treated with PARI and PAR4 inhibitors ( $18 \mu \mathrm{M}$ SCH79797, I mg/ml PAR4-blocking antibody, respectively). Thrombin ( $2 \mathrm{nM}$ ) was used as activator. * $\mathrm{p} \leq 0.05$. ${ }^{* *} \mathrm{p} \leq 0.0 \mathrm{I}$. All values are given as mean $\pm S D, n=10$.

\begin{tabular}{|l|l|l|l|l|l|}
\hline & Clotting time $(\mathbf{m i n})$ & $\begin{array}{l}\text { Time from clotting } \\
\text { to lysis start }(\mathbf{m i n})\end{array}$ & Lysis time $(\mathbf{m i n})$ & $\Delta \mathbf{G} \mathbf{( P a} / \mathbf{m i n})$ & $\mathbf{G} \mathbf{m a x}(\mathbf{P a})$ \\
\hline Control & $1 \mathrm{I} .13 \pm 1.75$ & $13.00 \pm 2.77$ & $29.07 \pm 5.21$ & $95.57 \pm 42.58$ & $1177.27 \pm 391.86$ \\
\hline PARI inhibition & $14.70 \pm 2.20 * *$ & $15.70 \pm 1.93 *$ & $36.37 \pm 4.57 * *$ & $116.31 \pm 38.86$ & $1363.11 \pm 266.46 *$ \\
\hline Control & $12.81 \pm 1.82$ & $15.33 \pm 4.00$ & $38.77 \pm 6.37$ & $124.48 \pm 59.88$ & $1298.88 \pm 289.42$ \\
\hline PAR4 inhibition & $20.09 \pm 4.35 * *$ & $19.25 \pm 3.40 *$ & $29.50 \pm 4.30 *$ & $82.22 \pm 23.13 * *$ & $1066.18 \pm 278.42 *$ \\
\hline Control & $12.81 \pm 1.82$ & $15.33 \pm 4.00$ & $38.77 \pm 6.37$ & $124.48 \pm 59.88$ & $1298.88 \pm 289.42$ \\
\hline PARI+4 inhibition & $20.61 \pm 2.85 * *$ & $16.33 \pm 3.76$ & $34.71 \pm 6.37$ & $87.42 \pm 33.62$ & $997.67 \pm 256.72$ \\
\hline
\end{tabular}

control sample set to $100 \%$. This is shown in Figure 3. The PAR1 and PAR4 inhibitors have different controls (sodium chloride and isotype antibody, respectively), which prevent a direct comparison of clotting and fibrinolysis times. Therefore the comparisons between PAR1 and PAR4 inhibition were made on the normalised data. All comparisons were made between samples and control for the same donor.

When PAR1 antagonist was added, the clotting times were prolonged by an average of $4 \mathrm{~min}$. The addition of PAR1 antagonist caused a significant increase in the clotting time and fibrinolysis time $(\mathrm{p} \leq 0.01)$ and in the time from clotting to the start of fibrinolysis ( $\mathrm{p} \leq 0.05$, compared with control).

The changes in clotting and fibrinolysis times caused by inhibition of the PAR4 receptor with the PAR4-blocking antibody are shown in Table 1 and, as a percentage of control, in Figure 3. Clotting times were significantly longer than those without the blocking antibody $(\mathrm{p} \leq 0.01)$. The time from clotting to fibrinolysis start was significantly increased compared with the control $(\mathrm{p} \leq 0.05)$, but in contrast to inhibition of PAR1 the fibrinolysis time was decreased $(\mathrm{p} \leq 0.05)$

In some experiments, samples from the blood incubated with a PAR1 antagonist, PAR4-blocking antibody or without inhibitor were activated with thrombin and analysed in the flow cytometer. This was done to confirm that we had managed to block the PAR receptors. The fibrinogen binding induced by $2 \mathrm{nM}$ thrombin was $27.0 \pm 4.2 \%, n=3$. With a PAR1 antagonist, the fibrinogen binding was almost completely inhibited with levels that were similar to the negative control ( $96 \pm 2 \%$ inhibition, $n=3$ ). The PAR4-blocking antibody inhibited the thrombin activation by $74 \pm 14 \%, n=4$.

\section{Effects of PARI and PAR4 inhibition on clot elasticity}

The results from the elasticity measurements are shown in Figure 4 and Table 1 . The $\Delta \mathrm{G}^{\prime}$ and $\mathrm{G}^{\prime}$-max were slightly increased when the PAR1 receptor was inhibited $(138 \pm 66 \%$ and $122 \pm 26 \%$ of control, respectively, $n=10$ ) although only the increase of $\mathrm{G}^{\prime}$-max was significant $(\mathrm{p} \leq 0.05)$. When the PAR4 receptor was inhibited, $\Delta \mathrm{G}^{\prime}$ and $\mathrm{G}^{\prime}-\mathrm{max}$ were decreased $(72 \pm 17 \%$ and $83 \pm 17 \%$, respectively, of control, $\mathrm{n}=10$ ). Both differences were significant, $\mathrm{p}<0.05$ for $\Delta \mathrm{G}^{\prime}$ and $\mathrm{p}<0.01$ for $\mathrm{G}^{\prime}$-max. When both receptors were inhibited simultaneously, $\Delta \mathrm{G}^{\prime}$ and $\mathrm{G}^{\prime}$-max seemed slightly, although not significantly, decreased as well, $81 \pm 33 \%$ and $84 \pm$
$19 \%$, respectively, of control $(\mathrm{n}=10)$.

\section{Effects of PARI and PAR4 inhibition on thrombin generation}

The lag time (which the manufacturer describes as the moment when thrombin formation starts) was significantly prolonged when PAR4 was inhibited and when both PAR1 and PAR4 were inhibited. The effect of PAR1 inhibition, however, was not significant (Fig. 5). The endogenous thrombin potential (ETP, area under the thrombogram) was slightly but significantly decreased when PAR1 was inhibited. The peak was not affected by PAR1 inhibition or dual PAR inhibition. PAR4 inhibition resulted in a

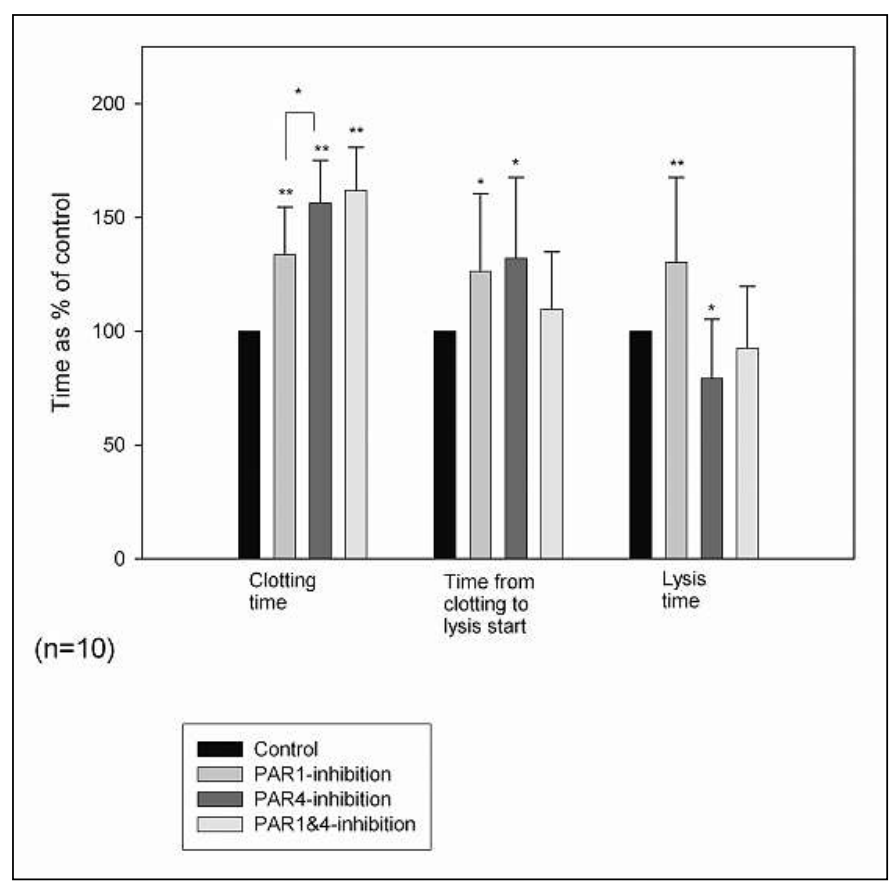

Figure 3: Fibrinolysis experiments with PARI and PAR4 in-

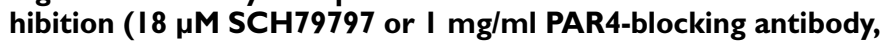
respectively). Thrombin ( $2 \mathrm{nM})$ was used as activator. The measurements were performed with FOR (free oscillation rheometry) on whole blood from ten healthy donors. The bar graph shows the mean \pm SD. $*_{p} \leq 0.05$ compared with control. $*^{*} p \leq 0.01$. Lysis time is the time from fibrinolysis start to end of fibrinolysis. 


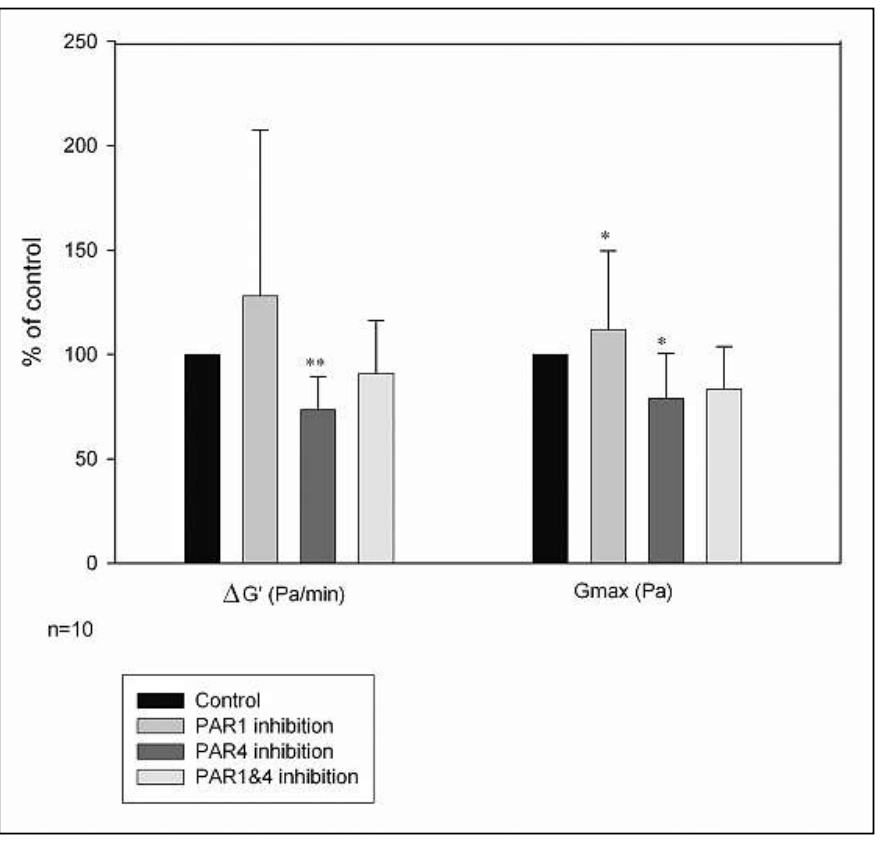

Figure 4: Elasticity measurements with PARI and PAR4 inhibitors ( 8 MM SCH79797 or I mg/ml PAR4-blocking antibody, respectively). Thrombin $(2 \mathrm{nM})$ is used as activator. The measurements are performed with FOR (free oscillation rheometry) on whole blood from ten healthy donors. The bar graph shows the mean $\pm S D$. ${ }_{p} \leq 0.05$ compared with control. ${ }^{* *} \mathrm{p} \leq 0.01$.

slight decrease in the peak height $(\mathrm{p}<0.05)$ but had no effect on the ETP (Fig. 5). Time to peak was significantly prolonged when PAR4, and PAR1 and PAR4 in combination were inhibited. The prolonged lag time, $120 \pm 13 \%(\mathrm{n}=13)$, corresponded to the prolongation in time to peak, $123 \pm 14 \%(\mathrm{n}=13)$.

\section{Discussion}

In the present study we wanted to investigate the relative impacts of PAR1 and PAR4 activation on platelet activation, blood coagulation, clot elasticity and fibrinolysis resistance.

The platelet activation measurements showed a difference between PAR1 and PAR4 activation in respect to fibrinogen binding. Both the percentage of fibrinogen-binding platelets and the MFI values for fibrinogen binding were higher with PAR4 activation. This difference may be related to coagulum elasticity, a hypothesis that is augmented by our elasticity results. Other results (28), obtained with aggregometry, indicate that PAR1 and PAR4 activation leads to the same degree of exposure of functional glycoprotein IIb/IIIa complexes (fibrinogen receptor) and aggregation. However, flow cytometry is a more sensitive and more quantitative method for determining the exposure of platelet receptors, which may explain the conflicting results.

Clotting times seem to be markedly influenced by PAR4, and were even more prolonged by PAR 4 inhibition than by PAR 1 inhibition. The control experiments with the PAR4-blocking antibody confirmed that this is a true PAR4 effect. In all our experiment settings control samples containing the same concentration of isotype antibody as PAR4 antibody were used to compensate

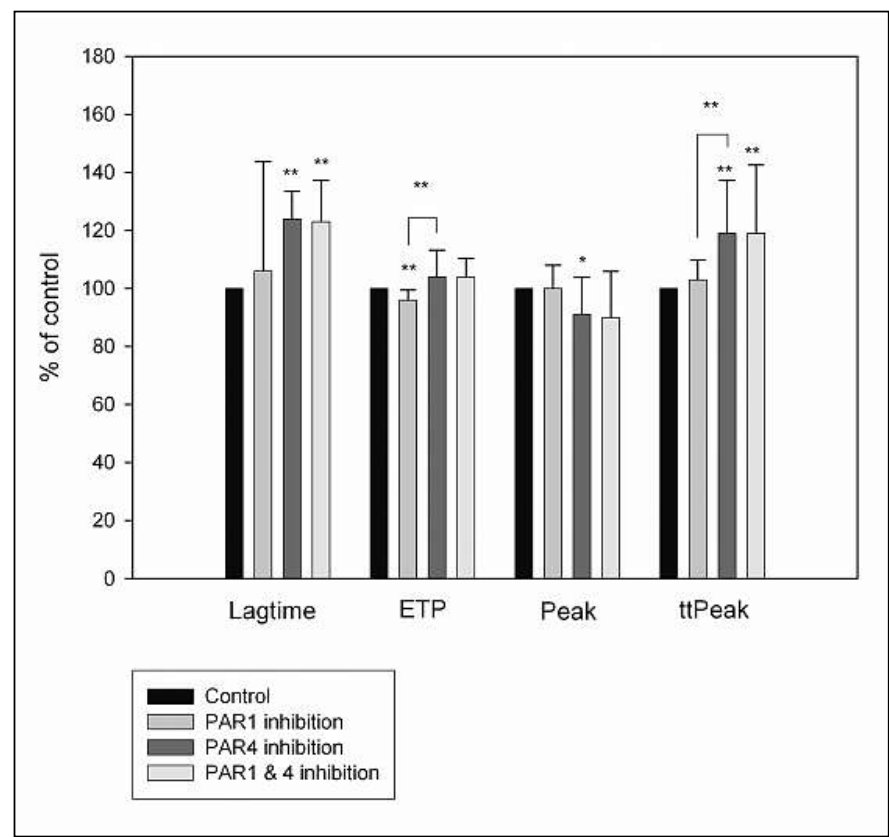

Figure 5: Thrombin generation measurements in PRP with PARI and PAR4 inhibitors (SCH79797 25.2 $\mu$ M, PAR4-blocking antibody $1.4 \mathrm{mg} / \mathrm{ml}$, a combination of both, or irrelevant antibody $1.4 \mathrm{mg} / \mathrm{ml}$ ). The measurements were performed on Fluoroskan fluorometer with Thromboscope software on PRP from I3 healthy donors. ${ }^{*} \leq 0.05$ compared with control. ${ }^{* *} p \leq 0.01$. The bar graph shows the mean $\pm S D$.

for unspecific effects that might be caused by the relatively high concentration of antibodies present in the samples; however, the effects observed were always negligible.

Platelet activation via PAR4 has been considered not to be of relevance in vivo, because the PAR1 receptor should have been activated already at much lower thrombin concentrations according to the biphasic model (11). If this was the case, it might be assumed that inhibition of PAR1 would substantially prolong clotting time and lag time for thrombin generation. However, inhibition of PAR4 had the greatest effect, which might indicate that this receptor has significant impact on platelet procoagulant properties even at low thrombin concentrations. Another group (28) has reported that PAR4 activation has no effect on clotting time, but they used a less potent activating peptide in a phospholipid-dependent coagulation assay. In contrast, in the present study the PAR4 receptors were inhibited because if an activating peptide is used in conditions in which anticoagulation is reversed, thrombin is formed, activating both PAR1 and PAR4 receptors. By inhibiting the PAR4 receptor, only PAR1 will be activated, thus enabling a true receptor-specific effect to be detected.

The thrombin generation measurements, in which no thrombin is present at the start of the experiments, clearly show that PAR4 inhibition affected the start of thrombin generation, once again indicating that PAR4 is involved early in the process when the thrombin concentrations are very low. It also indicates that PAR4 is likely relevant in the early phases of coagulation in vivo.

Data concerning the interactions between platelets and the fibrinolytic system are conflicting (reviewed by [29, 30]). Where- 
as some reports state that platelets have a protective effect on the coagulum, others have reported that the fibrinolysis proceeded faster in PRP than in platelet-poor plasma (31). In our experiments we have used whole blood rather than plasma, which has been used in other studies. Our results show a significant prolongation of the time between clotting and the start of the fibrinolysis both with PAR1 and PAR4 inhibition. It is possible that the available thrombin, rather than binding to the platelet PARs and acting as a platelet activator, acts on the thrombin-activated fibrinolysis inhibitor (TAFI) (32). If this is the case, it might explain why inhibition of the PARs delayed the start of the fibrinolysis process.

The results concerning the length of the fibrinolysis process may indicate that PAR1 and PAR4 have different effects on the ongoing fibrinolysis, but the large inter-individual variation makes it hard to tell whether this is a true effect or merely a lack of precision in the method. Because the ReoRox measures changes in frequency and damping of the oscillating cup, any detachment of the coagulum from the cup wall as the fibrinolysis continues leads to imprecise measurements of the state of the sample. This might make it difficult to precisely determine the time for the complete dissolution of the coagulum.

The elasticity of the clot was decreased by PAR4 inhibition, whereas inhibition of PAR1 increased the elasticity. The result with PAR4 inhibition indicates that platelets activated via PAR4 play a role in forming a normal structure of the coagulum, which is a process that follows after clotting. To our knowledge, no reports exist on effects on coagulum structure. However, if we relate the result of PAR4 inhibition affecting the elasticity of the coagulum with the flow-cytometric results in which PAR4 activation leads to more than twice as much platelet-fibrinogen binding than PAR1 activation, measured as a doubling of MFI values, it is plausible to suggest that this increase in platelet-fibrinogen binding is important for the coagulum elasticity. The crucial role of platelet-bound fibrinogen is underscored by the fact that blood from patients with Glanzmann's thrombastenia lacks clot retraction (33). The finding that the PAR4 receptor seems to play the major role of the two thrombin receptors is of specific interest in proposing a possible physiological role for PAR4. Other reports state that activation of PAR4 causes irreversible aggregation even in the presence of inhibitors to platelet $A D P$ receptor $\mathrm{P} 2 \mathrm{Y}_{12}$, which was not the case for PAR1. This suggests a mechanism for PAR4 in a more direct conversion of the fibrinogen receptor into the high-affinity conformation (17). However, our flow cytometry experiments indicate that the level of fibrinogen binding caused by PAR4 receptor activation cannot be fully mimicked by activation via PAR1 and the ADP receptors alone, as there were differences in maximum response even though the experiments were done in the absence of any ADP receptor inhibitor. In a previous study we showed that inhibition of the ADP receptors has an effect on clotting but not on fibrinolysis and elasticity parameters (21). Therefore we chose not to include ADP inhibitors in the experiments.

Differences in thrombin levels have been shown to affect the structure of the fibrin network formed (34), and the fibrin structure in turn has been shown to affect the fibrinolysis resistance (35). For these reasons, we also measured thrombin generation in PRP in the presence of the PAR inhibitors to estimate effects on the fibrin network structure. We found that PAR1 inhibition had little, if any, effect on thrombin generation, and that PAR 4 inhibition delayed the process. However, when the formation started, there were no differences in the slope of the curve or the total thrombin generation. This indicates that the changes observed after inhibition of PAR1 or PAR4 are not caused by differences in the fibrin network structure. The most likely explanation is that the inhibition affects the platelet in a way that affects fibrinolysis resistance or clot elasticity, presumably by inhibiting degranulation or cytoskeletal rearrangements. Previously published studies showing that about $90 \%$ of the elasticity effect is platelet dependent (36) also support the hypothesis that this is indeed the case.

Another finding in the present study was that PAR1 and PAR4 inhibition seemed to have opposite effects on several thrombin-generation and clot-elasticity parameters, which is interesting as the two receptors are currently believed to have the same intracellular signalling mechanism. A new report stating that activation of PAR4 but not PAR1 leads to a cytoskeleton-dependent calcium influx across the plasma membrane (37) supports the notion of differences in signalling pathways, an area that needs to be further explored in the near future.

In conclusion, we have found that PAR4 is most likely activated by low concentrations of thrombin during the initial phase of thrombin generation and is of importance for the clotting time. Furthermore, we have detected a possible physiological role for the PAR4 receptor in the stabilisation of the coagulum.

\section{Acknowledgements}

The authors wish to thank the blood donors and the personnel at the Blood Centre, Linköping University Hospital and the staff at the Haemostasis Group at the Department of Clinical Chemistry, University Hospital, Linköping, for their support. The authors also want to thank Anders Larsson at Immunsystem IMS AB (Uppsala, Sweden) for providing us with the antibody towards PAR4.

\section{References}

1. Monroe DM, Hoffman M. What does it take to make the perfect clot? Arterioscler Thromb Vasc Biol 2006; 26: 41-48.

2. Klages B, Brandt U, Simon MI, et al. Activation of G12/G13 results in shape change and Rho/Rho-kinasemediated myosin light chain phosphorylation in mouse platelets. J Cell Biol 1999; 144: 745-754.

3. Vassallo RR, Jr., Kieber-Emmons T, Cichowski K, et al. Structure-function relationships in the activation of platelet thrombin receptors by receptor-derived peptides. J Biol Chem 1992; 267: 6081-6085.

4. Xu WF, Andersen H, Whitmore TE, et al. Cloning and characterization of human protease-activated receptor 4. Proc Natl Acad Sci USA 1998; 95: 6642-6646.

5. Vu TK, Wheaton VI, Hung DT, et al. Domains specifying thrombin-receptor interaction. Nature 1991; 353: 674-677.
6. Gerszten RE, Chen J, Ishii M, et al. Specificity of the thrombin receptor for agonist peptide is defined by its extracellular surface. Nature 1994; 368: 648-651.

7. Chen J, Ishii M, Wang L, et al. Thrombin receptor activation. Confirmation of the intramolecular tethered liganding hypothesis and discovery of an alternative intermolecular liganding mode. J Biol Chem 1994; 269 : 16041-16045.

8. Vu TK, Hung DT, Wheaton VI, et al. Molecular 
cloning of a functional thrombin receptor reveals a novel proteolytic mechanism of receptor activation. Cell 1991; 64: 1057-1068.

9. Faruqi TR, Weiss EJ, Shapiro MJ, et al. Structurefunction analysis of protease-activated receptor 4 tethered ligand peptides. Determinants of specificity and utility in assays of receptor function. J Biol Chem 2000; 275: 19728-19734.

10. Kahn ML, Nakanishi-Matsui M, Shapiro MJ, et al Protease-activated receptors 1 and 4 mediate activation of human platelets by thrombin. J Clin Invest 1999; 103: 879-887.

11. Covic L, Gresser AL, Kuliopulos A. Biphasic kinetics of activation and signaling for PAR1 and PAR4 thrombin receptors in platelets. Biochemistry 2000; 39: 5458-5467.

12. Vanhoorelbeke K, Ulrichts H, Romijn RA, et al. The GPIbalpha-thrombin interaction: far from crystal clear. Trends Mol Med 2004; 10: 33-39.

13. Nylander S, Mattsson C. Thrombin-induced platelet activation and its inhibition by anticoagulants with different modes of action. Blood Coagul Fibrinolysis 2003; 14: 159-167.

14. Seeley S, Covic L, Jacques SL, et al. Structural basis for thrombin activation of a protease-activated receptor: inhibition of intramolecular liganding. Chem Biol 2003; 10: 1033-1041.

15. Kinlough-Rathbone RL, Perry DW, Guccione MA et al. Degranulation of human platelets by the thrombin receptor peptide SFLLRN: comparison with degranulation by thrombin. Thromb Haemost 1993; 70: 1019-1023.

16. Sambrano GR, Huang W, Faruqi T, et al. Cathepsin $\mathrm{G}$ activates protease-activated receptor- 4 in human platelets. J Biol Chem 2000; 275: 6819-6823.

17. Covic L, Singh C, Smith H, et al. Role of the PAR4 thrombin receptor in stabilizing platelet-platelet aggregates as revealed by a patient with Hermansky-Pudlak syndrome. Thromb Haemost 2002; 87: 722-727.
18. Bohlin L. Method of measuring rheological properties and rheometer for carrying out the method, in PCT (Patent Cooperation Treaty) publication number WO94/08222. 1994, Aktiebolaget Medicinsk Reologi Lund: United States.

19. Bohlin L. Bearing device, in PCT (Patent Cooperation Treaty) publication number WO98/54475. 1998, Global Hemostasis Institute.

20. Ranby M, Ramstrom S, Svensson PO, et al. Clotting time by free oscillation rheometry and visual inspection and a viscoelastic description of the clotting phenomenon. Scand J Clin Lab Invest 2003; 63: 397-406.

21. Ramstrom S, Ranby M, Lindahl T. Effects of inhibition of P2Y1 and P2Y12 on whole blood clotting, coagulum elasticity and fibrinolysis resistance studied with free oscillation rheometry. Thromb Res 2003; 109: 315-322.

22. Lindahl TL, Festin R, Larsson A. Studies of fibrinogen binding to platelets by flow cytometry: an improved method for studies of platelet activation. Thromb Haemost 1992; 68: 221-225.

23. Akita EM, Nakai S. Comparison of four purification methods for the production of immunoglobulins from eggs laid by hens immunized with an enterotoxigenic $E$. coli strain. J Immunol Methods 1993; 160: 207-214.

24. Brass LF, Pizarro S, Ahuja M, et al. Changes in the structure and function of the human thrombin receptor during receptor activation, internalization, and recycling. J Biol Chem 1994; 269: 2943-2952.

25. Molino M, Bainton DF, Hoxie JA, et al. Thrombin receptors on human platelets. Initial localization and subsequent redistribution during platelet activation. J Biol Chem 1997; 272: 6011-6017.

26. Molino M, Blanchard N, Belmonte E, et al. Proteolysis of the human platelet and endothelial cell thrombin receptor by neutrophil-derived cathepsin G. J Biol Chem 1995; 270: 11168-11175.
27. Hemker HC, Al Dieri R, Beguin S. Thrombin generation assays: accruing clinical relevance. Curr Opin Hematol 2004; 11: 170-175.

28. Andersen H, Greenberg DL, Fujikawa K, et al. Protease-activated receptor 1 is the primary mediator of thrombin-stimulated platelet procoagulant activity. Proc Natl Acad Sci USA 1999; 96: 11189-11193.

29. Devine DV, Carter CJ. Profibrinolytic and antifibrinolytic effects of platelets. Coron Artery Dis 1995; 6 : 915-922.

30. Korbut R, Gryglewski RJ. Platelets in fibrinolytic system. J Physiol Pharmacol 1995; 46: 409-418.

31. Lenich C, Liu JN, Gurewich V. Thrombin stimulation of platelets induces plasminogen activation mediated by endogenous urokinase-type plasminogen activator. Blood 1997; 90: 3579-3586.

32. Bajzar L. Thrombin activatable fibrinolysis inhibitor and an antifibrinolytic pathway. Arterioscler Thromb Vasc Biol 2000; 20: 2511-2518.

33. Glanzmann E. Hereditäre hämorragische Thrombasthenie. Ein Beitrag zur Pathologie der Blutplättchen Jahr Kinderh 1918; 88: 113-141.

34. Blombäck B, Carlsson K, Fatah K, et al. Fibrin in human plasma: gel architectures governed by rate and nature of fibrinogen activation. Thromb Res 1994; 75: 521-538.

35. Collet JP, Park D, Lesty C, et al. Influence of fibrin network conformation and fibrin fiber diameter on fibrinolysis speed: dynamic and structural approaches by confocal microscopy. Arterioscler Thromb Vasc Biol 2000; 20: 1354-1361.

36. Tynngård $\mathrm{N}$, Lindahl $\mathrm{T}$, Ramström $\mathrm{S}$, et al. Effects of different blood components on clot retraction analysed by measuring elasticity with a free oscillating rheometer. Platelets 2006; 17: 545-554.

37. Harper MT, Sage SO. Actin polymerisation regulates thrombin-evoked $\mathrm{Ca}(2+)$ signalling after activation of PAR-4 but not PAR-1 in human platelets. Platelets 2006; 17: 134-142. 